\title{
Theoretical studies on space debris recycling and energy conversion system in the International Space Station
}

\author{
Amrith Mariappan ${ }^{1,2,3} \odot$ | V. R. Sanal Kumar ${ }^{1,4,5}{ }^{\infty}$ | Stephen J. Weddell ${ }^{6} \odot$ | Vishnu \\ Anand Muruganandan ${ }^{1,6}$ @ $\mid$ In-Seuck Jeung ${ }^{7} \odot$
}

${ }^{1}$ Department of Aeronautical

Engineering, Kumaraguru College of

Technology, Coimbatore, India

${ }^{2}$ AARIK Aerospace Company Pvt. Ltd.,

Chennai, India

${ }^{3}$ Department of Mechanical and Aerospace Engineering, University at Buffalo, Buffalo, New York, USA

${ }^{4}$ Aerospace Propulsion Group, Indian Institute of Science, Bangalore, India

${ }^{5}$ Vikram Sarabhai Space Centre, Indian Space Research Organisation,

Trivandrum, India

${ }^{6}$ Department of Electrical and Computer Engineering, University of Canterbury, Christchurch, New Zealand

${ }^{7}$ Department of Aerospace Engineering, Seoul National University, Seoul, Republic of Korea

\section{Correspondence}

Amrith Mariappan, AARIK Aerospace Company Pvt. Ltd., Chennai 600 048,

Tamil Nadu, India.

Email: amrithma@buffalo.edu

V. R. Sanal Kumar, Vikram Sarabhai

Space Centre, Indian Space Research

Organisation, SC CA No. 6301/2013,

Trivandrum 695 022, Kerala, India.

Email:vr_sanalkumar@yahoo.co.in

\begin{abstract}
The space debris management and alleviation in the microgravity environment is a dynamic research theme of contemporary interest. Herein, we provide a theoretical proof of the concept of a lucrative energy conversion system that is capable of changing the space debris into useful powders in the International Space Station (ISS) for various bids. A specially designed broom is adapted to collect the space debris of various sizes. An optical sorting method is proposed for the debris segregation in the ISS by creating an artificial gravitational field. It could be done by using the frame-dragging effect or gravitomagnetism. An induction furnace is facilitated for converting the segregated metal-scrap into liquid metal. A fuel-cell aided water atomization method is proposed for transforming the liquid debris into metal powder. The high-energetic metal powders obtained from the space debris could be employed for producing propellants for useful aerospace applications, and the silicon powder obtained could be used for making soil for fostering the pharmaceutical-flora in the space lab in the future aiming for the scarce-drug discoveries for high-endurance health care management. The proposed energy conversion system is a possible alternative for the space debris extenuation and its real applications in orbiting laboratories through the international collaboration for the benefits to humanity.
\end{abstract}

\section{K E Y W O R D S}

drugs discovery, energy conversion system in microgravity, medicinal plants in ISS, pharmaceutical flora, space debris mitigation, space lab

\section{1 | INTRODUCTION}

The International Space Station (ISS) is a unique scientific podium and an orbiting laboratory that has facilitated interdisciplinary researchers in 106 countries to conduct various in vitro trials in microgravity. Although each ISS partner has varied scientific goals, the collective objective is to encompass the skill and knowledge reaped to benefit all humankind. ${ }^{1,2}$ This is predominantly factual for nurturing medicinal plants in ISS for scarce-drug discoveries for the benefits of humanity. ${ }^{3}$ This article is a part of the scientific odyssey that resulted from a collaboration among members from 
various research groups from physical, chemical, material and biological sciences. Literature review reveals that through fundamental research and development a few products and services derived from space station activities are entering the souk and furthering healthy and peaceful life on Earth, ${ }^{1}$ which is motivating us to propose more challenging research in ISS. It is evident from the executive summary of ISS, which encapsulates the achievements of innovative research on the orbiting laboratory that had created a positive impact on the quality of life on Earth and the future scope of the interdisciplinary researches globally for creating an impact on scientific advancement. ${ }^{1-16}$ Herein we conduct theoretical studies for providing the proof of the concept of space debris recycling and energy conversion system in a microgravity environment with an intention to carry out real-time experiments in the space platform through the multinational collaboration with wide scope and benefits to humanity.

The emerging application of outer space for the progression of the standard of living and quest for wisdom has led to the growth of space debris or space junk in orbits where the large number of satellites is operational. Various reports and industrial engineering data on the usefulness of the prevailing debris extenuation methods are inadequate for a realistic conclusion. ${ }^{4-16}$ The present trend of global space activities indicates that in the ensuing decades' huge volumes of space debris will be in orbit and there is a need to update the debris alleviation normal exercises to stimulate competent and active practices to better abate the risks from space debris for the benign maneuvers of future space missions. ${ }^{4-7,14}$ The fact is that even if all the upcoming space launches are called off, the space debris that already exists will be tendering threats for numerous decades to come before all of them re-enter the earth and burn off. ${ }^{12-14}$ Deepaa Anandhi et al ${ }^{14}$ reported the necessity for a quick imperative operation on the space debris extenuation separately or collectively by the diverse beneficiary organizations employing the orbital space for achieving future global needs. Though numerous ongoing debris de-orbiting programs are intact, the engineering data on the usefulness of the prevailing debris extenuation procedures are inadequate for a reliable judgment. ${ }^{15}$ Briefly, an enhanced volume of space debris has become a menace to operational satellites, ISS and various space missions. Although many studies have been reported over the decades on space debris management and alleviation, the space system designers reported that there are no foolproof techniques for tracking and mitigation of space debris having the object size between 1 and $10 \mathrm{~cm}$, which could cause significant damage to operational satellites, future space vehicles and the ISS. ${ }^{15}$ Literature review reveals that there are no rewarding methods to pooling randomly moving space debris and further its transformation into fuels in the ISS. Weddell et $\mathrm{al}^{16}$ had come up with a multi-object adaptive optics method to advance the resolution of the space debris images for reducing its tracking intricacies. Admittedly, the state-of-the-art modus operandi is inadequate for the complete mitigation of space debris owing to the fact that there may be some parts that would be liberated and orbiting for obvious causes beyond control of the space agencies. This is particularly true when a physical part of the space vehicle left in geostationary transfer orbit during a multiple payload mission. Therefore, it is essential, rather enviable, perhaps predestined for inventing lucrative and efficient methods of space debris mitigation. The United Nations (UN) committee on the peaceful uses of outer space reported that the most challenging part of the space operations is the collision avoidance. It also reported that the space debris curing issues certainly entails joint action by all participants. ${ }^{9}$

The central idea of the space broom, governed by the dual-head electromagnetic (DHEM) device, ${ }^{17}$ is to mitigate the intermediate size of the space debris object, which could otherwise pierce holes in the structure of the ISS and operational satellites, particularly in the low earth orbit. It is estimated that the space debris could crash any space vehicle at a velocity greater than $48280 \mathrm{~km} / \mathrm{h} .{ }^{15}$ Hao Jiang et $\mathrm{al}^{18}$ carried out tests in microgravity and reported that robotic grippers based on dry adhesion are a workable option for purging space debris in low earth orbit. The DHEM space broom with variable sweeping speed developed by Sanal Kumar et $\mathrm{a}^{17}$ could be a useful method for the space debris mitigation and its collection for recycling it in the orbiting space lab through the lucrative energy conversion methods. The DHEM space broom could be redesigned for capturing the inactive satellites, rocket fragmentation debris, and other nonfunctional objects or debris pieces from the low earth orbit. The environmental report (2019) of the European Space Agency (ESA) highlighted that space debris mitigation requires a level playing field to achieve long-term stability. The ESA highlighted in its annual space environment report (2019) that the production of space debris via impacts and blasts in orbit could lead to an exponential growth in the volume of artificial objects in space. ${ }^{19}$ Therefore, the menace of space debris to the future of spaceflight created the need for a set of internationally accepted space debris mitigation measures. ${ }^{20}$ Recently the ESA emphasized the need of world-wide devotion to invoking space debris alleviation measures lucratively. The accessible global literature reveals that no one attempted yet (2020), the recycling technique to change the debris into powders in the ISS for multiple applications. ${ }^{12}$

Report (2019) reveals that India contributed around 400 pieces of orbital debris through their anti-satellite missile test (ASAT), which increases the risk of threat to the ISS on the order of $44 \% .{ }^{15}$ Since the test was done in a low altitude to 
restrict the orbital lifespan of ensuing debris, the space agency claimed that whatever debris that is generated would decay and fall back onto the earth within weeks and the ISS will not be at risk, as it is in the higher orbit. However, there are possibilities of the orbital lifting of space debris due to missile impact, which could create threat to the ISS. Therefore, in future such tests must be avoided by all the space agencies or must be done with caution as the ISS is a human inhabitant and an orbiting laboratory, which is to be protected with zero-risk. It is well known that the nonresponsive satellites are categorized as the high-risk space debris to the operational satellites and the ISS. The primary structure of most of the satellites consists of aluminum, beryllium, stainless steel, and titanium. The appendage booms, antenna dishes (made of aluminum/steel), platforms, solar panels (made of silicon/germanium), and support trusses, are common secondary structures. The mounting brackets, cable supports, copper wiring and connector panels, electronic boxes, and silicon made printed circuit board are categorized as tertiary structures. ${ }^{21}$ The literature review reveals that Aluminum 6061, a potential fuel for solid propellant, is used as the primary structure of the CubeSats. ${ }^{22}$ Therefore, any combined method to mitigate and recycle the space debris with an innovative energy conversion method could create a win-win situation, which is attempted herein.

In this article a cogent conceptual method has been suggested for converting the space debris into lucrative solid fuels in the ISS with artificial gravitational field. Note that Tajmar ${ }^{23}$ reported two different system designs that could generate an artificial gravitational field using frame-dragging effect on space-time, predicted by Albert Einstein's general theory of relativity, or gravitomagnetism. The space broom operated by a DHEM device is used for capturing the space debris from the space environment. ${ }^{17}$ An optical sorting method will be used in the ISS for segregating the collected debris into individual material and metal scraps. Using an electric channel induction furnace, the separated metal scraps are converted into the molten metal form. Further, a lucrative water atomization system operated with a fuel cell has been adopted for transforming the molten metal into powder form, which produce the end products, namely, the metal powder and the water. The segregated selected powders are utilized for making solid propellant for chemical propulsion. The specially separated silicon powders are used for building feigned soil for nurturing pharmaceutical flora in the ISS for the scarce drug discovery for the high-endurance health care management. ${ }^{3,24,25}$ An inclusive layout of the proposed methodology for space debris mitigation and the energy conversion technique are described in the subsequent section.

\section{2 | METHODOLOGY}

The comprehensive layout of the energy conversion system used for changing the space debris into fuel and feigned soil is shown in Figure 1A,B. The detailed report of an analytical case study, along with the requirements of power and water in the ISS for separating aluminum and silicon powder from the space debris, is presented in the subsequent section (see Table 1). The following lucrative steps are proposed for the collection of composite space debris and further its conversion into powder form for various applications in physical, chemical, pharmaceutical, and biological sciences.

\section{1 | Debris collection method}

The DHEM space broom proposed by Kumar et $\mathrm{al}^{17}$ is chosen as a profitable method for the collection of space debris to the ISS. The feedback-controlled variable sweeping speed DHEM space broom will be capable of capturing all the space debris nearing to the ISS including the nonfunctional objects having an average size between 1 and $10 \mathrm{~cm}$, which are moving with different velocities and directions and polluting the space environment and creating risk to operational satellites and space vehicles. Note that the debris capturing net made of Graphene material, and the bidirectional plasma thruster, ${ }^{26}$ could be other options for space debris collection for the operational protection redundancy. The technology of the net proposed by $\mathrm{ESA}^{27}$ in this regard could be used for capturing the debris after decelerating it using plasma thrusters.

\section{2 | Debris sorting method}

A mechatronics control device, with cameras and/or lasers, is proposed for separating the irregular-shaped debris into discrete materials, namely, magnesium, aluminum, etc. ${ }^{28}$ The device could achieve to sort out 2000 to 3000 particles per second, with a minimum power consumption $(\sim 1 \mathrm{~kW}) .^{29,30}$ 


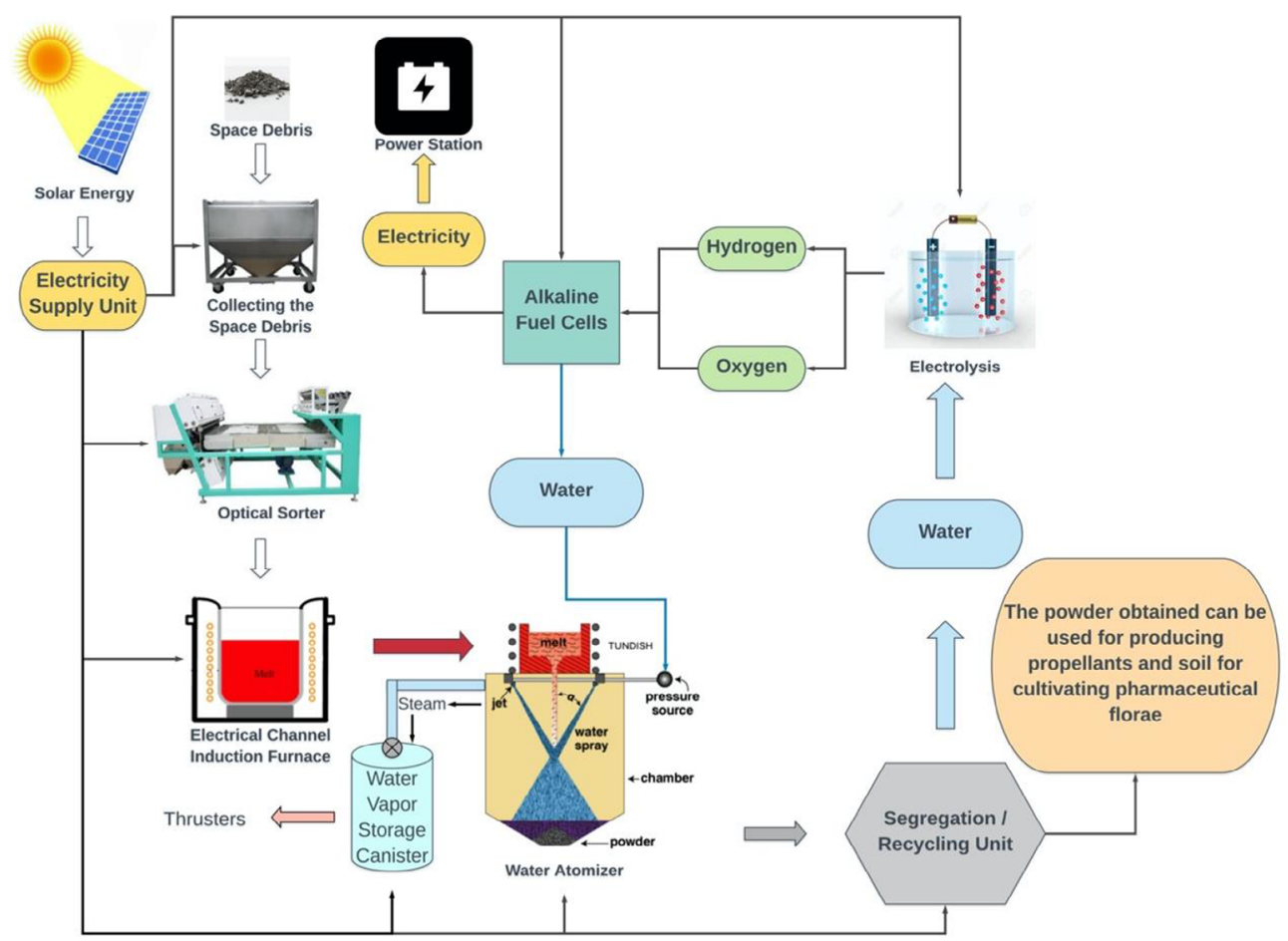

(A)

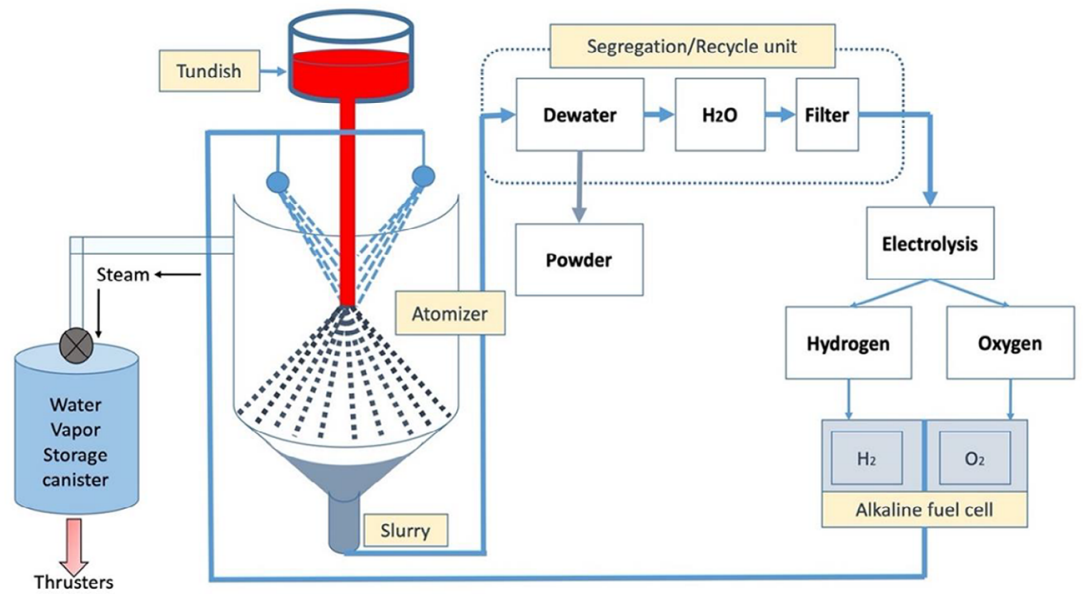

(B)

F I G U RE 1 (A) The proposed process layout for converting the space debris into powders. (B) The proposed process layout of the water atomization process

TA B L E 1 Power and water requirements for transforming $1 \mathrm{~kg}$ of aluminum into fuel ${ }^{15}$

\begin{tabular}{|c|c|c|c|c|}
\hline Process & Power (Watt) & Water $(\mathrm{L} / \mathbf{k g})$ & Temperature $\left({ }^{\circ} \mathbf{C}\right)$ & Pressure (MPa) \\
\hline Segregation & $\begin{array}{l}1.85 \times 10^{-3} \\
\quad(\text { Insignificant })^{\mathrm{a}}\end{array}$ & - & 40 & 0.70 \\
\hline Liquefaction & $273.33^{\mathrm{b}}$ & - & $750^{\mathrm{b}}$ & 0.097 \\
\hline $\begin{array}{l}\text { Liquid alloy to powder } \\
\text { conversion }\end{array}$ & $3000-5000^{\mathrm{b}}$ & $12^{\mathrm{b}}$ & $750-1000$ & 1.03 \\
\hline $\begin{array}{l}\text { Recycling unit (Filter and } \\
\text { dewater) }\end{array}$ & $\begin{array}{l}18000(1500 \mathrm{~W} / \mathrm{L} \text { of } \\
\text { water })\end{array}$ & $\begin{array}{l}\text { Recycling of the generated } \\
\text { water }\end{array}$ & $\begin{array}{l}24 \text { for filter and } 55 \text { for } \\
\text { dewater }\end{array}$ & 0.101 \\
\hline Electrolysis & $50000^{c}$ & & $60-80$ & 3.0 \\
\hline Bacon fuel cell & 33330 & $9^{c}$ & 90 & 0.101 \\
\hline
\end{tabular}

${ }^{a}$ for administering of $1 \mathrm{~kg}$ scarp in the space lab.

${ }^{\mathrm{b}}$ for administering of $1 \mathrm{~kg}$ aluminum.

${ }^{\mathrm{c}}$ Hydrogen. 


\section{3 | Debris melting method}

The amount of electrical energy required for the electrical channel induction furnace for melting the collected debris in ISS is estimated onboard using an algorithm with traditional thermodynamics' equations. The evolved gases from the molten debris are collected in separate canisters for the profitable design of the space thrusters for numerous applications onboard and off board, which comprises the desirable orbital tweaks of the ISS. The entire system will be in a capsule facilitated with an artificial gravity generator to create a gravity-induced free-fall of fluids. As stated earlier, an artificial gravity could be created using an artificial gravitational field using frame-dragging or gravitomagnetism ${ }^{23}$ or by invoking a centripetal force.

\section{4 | The powder fuel production}

A well-designed tundish is equipped in the ISS for storing the molten debris (see Figure 1B), and for converting the molten debris into small granules, a high-velocity water jet is facilitated in the atomization process in the space lab with multiple nozzles. The small granules could be placed in the alloy powder box after sorting out, and the water will be recycled through the dewatering system and filters. The collected granules are dried, and the sizes of the granules are regulated according to onboard applications. A loss of 3\% to 5\% is anticipated during the sieving of powders. The required water for the atomization administration is acquired from the proposed recycling, alkaline fuel cell, and electrolysis methods. The proposed electrolysis method is the alkaline water electrolyzer, which could operate at a low temperature $\left(80^{\circ} \mathrm{C}-200^{\circ} \mathrm{C}\right)$ with an efficiency of $70 \%$ to $80 \%$. The proposed system is capable to prevent powder oxidation and thermal self-ignition. ${ }^{31}$ Note that until recently (2019) the water atomization process was not used to creating aluminum and aluminum alloy powders primarily due to the anticipated detonation risk due to the secretion of hydrogen as a result of powder interaction with water. Furthermore, the water atomization process was not, recommended due to the apprehension of powder oxidation and the deterioration of powder properties. Admittedly, these problems have been resolved at the Institute for Problems of Materials Science (Kiev, Ukraine). ${ }^{31}$

In our system, the heat energy obtained from the electrolysis process is used for drying the powders. The desired powders are separated with an objective for creating feigned soil in the ISS for cultivating pharmaceutical flora. Furthermore, the other selected metal powders are mixed with oxidizers and binders for making solid propellants for chemical propulsion. The powders, essentially aluminum, obtained with the desirable properties of solid propellants could be used for micro-thrusters for nanosatellites or devising other propulsion systems in the space lab. The silicon powder segregated from the debris powder could be used for making artificial soil in the ISS for vegetation as it plays important roles in mineral nutrition of plants. Note that silicon fertilizers today are very common in many crop production systems worldwide as it shows the significant amount of evidence in improving crop productivity. ${ }^{32}$ The comprehensive process layout highlighting the water atomization process is shown in Figure 1B. As mentioned earlier, the water atomization process and the other systems will be placed in a capsule where the artificial gravity environment persists. In this study, we are suggesting a water-cooling method for cooling down the system. The steam evolved during the process will be collected in a different water vapor storage canister. The steam will be regulated in the gaseous phase and will be used for the selective thrust-vectoring of the space station/ISS. Alternatively, steam evolved during the process can also be recycled and used as water resources for the atomization process. The temperature inside the capsule is maintained using the Active Thermal Control System which is currently used in the ISS to regulate the temperature. ${ }^{33}$ However, a further experimental study on water atomization and the cooling system in a microgravity environment is required for its qualification.

\section{3 | AN ANALYTICAL CASE STUDY}

In our case study $1 \mathrm{~kg}$ of aluminum powder is selected for conversion into useful fuel onboard. It is evident from Figure 2 that aluminum alloys are the major constituent of the space debris, ${ }^{34}$ which often collide with the ISS. Note that using the recommended technique (see Figure 1A,B), we estimated that, about $97 \%$ of aluminum powder could be acquired from the hoarded aluminum debris. A loss of $3 \%$ to $5 \%$ is anticipated after the water atomization process because of the sieving.

Note that by varying the operating and design parameters of the water atomization process like water spray pressure/speed, melt temperature, apex angle, and spray configuration ${ }^{31,35,36}$ we could achieve the desired size of the powder/granule. 


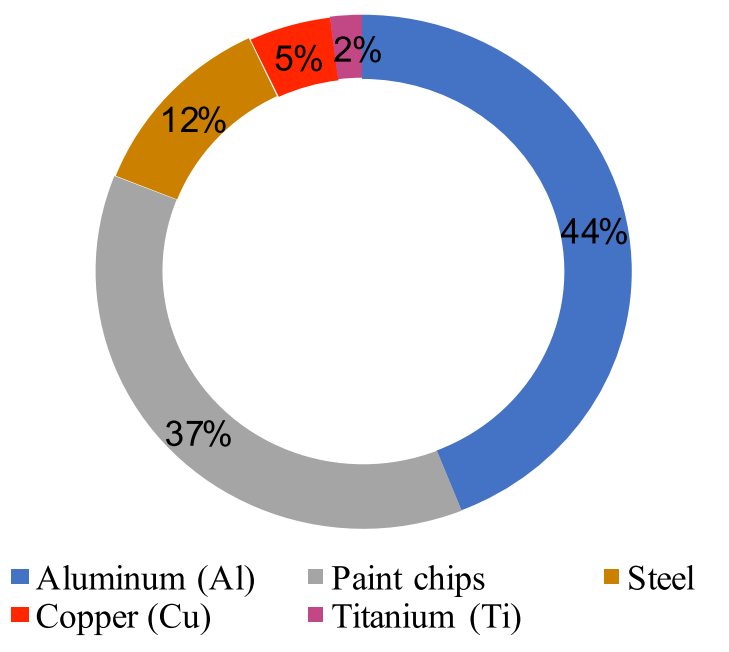

F I G U R E 2 A circle graph is demonstrating the percentage of materials that frequently blow on International Space Station

The process layout is depicted in Figure 1A,B. The required amount of electric power, water, heat, and the scale of pressure for converting the $1 \mathrm{~kg}$ of aluminum debris into fuel are highlighted in Table 1 . In order to process $1 \mathrm{~kg}$ of debris in a visual separator, an amount of $1.85 \mathrm{~mW}$ power is required at an operating temperature of $40^{\circ} \mathrm{C}$ at a pressure of $700 \mathrm{kPa}$.

An amount of 273.33 watt power is required for melting $1 \mathrm{~kg}$ of aluminum in the ISS at a temperature of $750^{\circ} \mathrm{C}$ and pressure of $96.52 \mathrm{kPa}$. Additionally, $750^{\circ} \mathrm{C}$ to $1000^{\circ} \mathrm{C}$ range heating system is required to retain aluminum in the liquid state at a pressure of $1.03 \mathrm{MPa}$ in the atomization process of $12 \mathrm{~L}$ of water, obtained from the alkaline fuel cell, at an electric energy consumption of 3 to $5 \mathrm{~kW}$. The potassium hydroxide is used as an electrolyte in the alkaline fuel cells at a temperature of $90^{\circ} \mathrm{C}$ at a pressure of $101.35 \mathrm{kPa}$. During this process $9 \mathrm{~L}$ of water and $33.33 \mathrm{~kW}$ of electricity are acquired as derivatives for $1 \mathrm{~kg}$ of hydrogen. The required amount of water is generated from the Bacon fuel cell for the atomization process. The estimated electric power needed for atomization, dewatering and filtering processes is $1.5 \mathrm{~kW}$. Note that a temperature of $55^{\circ} \mathrm{C}$ for dewatering ${ }^{37}$ and $24^{\circ} \mathrm{C}$ for filtering must be maintained in the system. The water is segregated into hydrogen and oxygen with the aid of the potassium hydroxide as an electrolyte at an energy consumption of $50 \mathrm{~kW}$ for $1 \mathrm{~kg}$ of hydrogen at a temperature range of $60^{\circ} \mathrm{C}$ to $80^{\circ} \mathrm{C}$, and at a pressure of $3 \mathrm{MPa}$. The generated hydrogen and oxygen are permitted to recycle in the onboard system to produce the water continuously for the water atomization process. The required powder, as an end product with desirable size, is obtained through appropriate sieving. Note that, if necessary, hydrogen gas could be either transported from the earth or obtained from space by utilizing the Bussard's ramjet. ${ }^{38}$

The solar energy conversion system is invoked for an efficient power generation, as the ISS has $2500 \mathrm{~m}^{2}$ solar panel, which could produce up to 84 to $120 \mathrm{~kW} .{ }^{39}$ Additionally, the fuel cell could contribute $33.33 \mathrm{~kW}$ of electricity, which mainly utilized for the recycling process. In the proposed technique, a total amount of $40 \mathrm{~kW}$ is required for processing 1 $\mathrm{kg}$ of aluminum. It is estimated that up to $1 \mathrm{~kW}$ power can be generated using a solar panel with one square meter area.

The satellite, named SNUSAT-2, a 3 U CubeSat designed and developed by the Seoul National University (SNU), South Korea for remote sensing is selected for our analytical case study. The main elements and the connected materials employed in the SNUSAT-2 are given in Table 2. Table 3 gives the result for the case study which has been carried out for the two different satellites. It is evident from the component details that once this SNUSAT-2 becomes nonoperational, it gives $1350 \mathrm{~g}$ of aluminum powder. In the case of a nonoperational Vanguard- $1^{40}$ we could collect an amount of $1420 \mathrm{~g}$ of aluminum through recycling, which could be converted into fuels for spacecraft propulsion.

\section{4 | CONCLUDING REMARKS}

A theoretical proof of the concept complemented with the pragmatic methodological approach has been established herein for converting space debris lucratively into fuels and also for building soil from silicon powder for fostering the pharmaceutical flora in the space lab of ISS for the drug discoveries. During the recycling process at the artificial gravity condition, the evolved gases could be stored in the canisters for devising thrusters for various aerospace propulsion applications. Using these thrusters, the ISS could be shifted to the subsequent orbit after mitigating all space debris from the nearest surroundings. Briefly, the recycling energy conversion system proposed herein could be utilized for the possible orbital trajectory changes of space labs. Through our analytical estimation we concluded that $1 \mathrm{~kg}$ of aluminum debris 
TA B L E 2 The components and the connected materials used in the SNUSAT-2

\begin{tabular}{|c|c|c|c|c|c|}
\hline Elements & Constituents & Mass per unit (g) & Amount (Nos.) & Allowance $(\% \pm)$ & Overall mass (g) \\
\hline Earth Sensor & $\mathrm{Al}, \mathrm{FR}-4, \mathrm{Cu}$ & 50 & 4 & 10 & 220 \\
\hline Star tracker & $\begin{array}{l}\text { Baffle material, Carbon } \\
\text { nanotube coating, } \mathrm{Cu}\end{array}$ & 50 & 1 & 10 & 55 \\
\hline GPS & $\mathrm{Al}, \mathrm{FR}-4, \mathrm{Cu}, \mathrm{Si}$ & 50 & 1 & 5 & 52.5 \\
\hline EPS board & Polystyrene & 105 & 1 & 5 & 110.25 \\
\hline Batteries & Lithium-Polymer, FR-4 & 256 & 1 & 5 & 288.8 \\
\hline Solar Panel & $\mathrm{Ge}$ & 100 & 4 & 10 & 440 \\
\hline UHF antenna & $\mathrm{Al}, \mathrm{FR}-4, \mathrm{Cu}$ & 100 & 1 & 5 & 105 \\
\hline Structure & $\mathrm{Al}$ & 500 & 1 & 10 & 550 \\
\hline On board Computers' & $\mathrm{Al}, \mathrm{Cu}, \mathrm{Si}, \mathrm{FR}-4$ & 55 & 1 & 5 & 57.75 \\
\hline EPOIS & Camera material & 1000 & 1 & 10 & 1100 \\
\hline Thrusters & $\mathrm{Al}$, propellants & 500 & 1 & 10 & 550 \\
\hline TOTAL & & 3063 & & & 3915.65 \\
\hline
\end{tabular}

Abbreviations: Al, Aluminum; Cu, Copper; Ge, Germanium; Si, Silicon.

Source: APCL, Aerospace Engineering; SNU, Seoul, The Republic of Korea.

TA B L E 3 Case study

\begin{tabular}{|lll|}
$\begin{array}{l}\text { Satellites } \\
\text { Classification }\end{array}$ & $\begin{array}{l}\text { Quantity of debris taken } \\
\text { for the recycling/material } \\
\text { used for recycling }(\mathrm{g})\end{array}$ & $\begin{array}{l}\text { Quantity of debris powder } \\
\text { yield from the recycling } \\
\text { process }(\mathrm{g})\end{array}$ \\
\hline SNUSAT-2 & 1392/Al & 1350 \\
Vanguard-1 & 1464/Al & 1420 \\
\hline
\end{tabular}

could produce approximately 0.96 to $0.98 \mathrm{~kg}$ of aluminum powder for producing valuable fuel for chemical propulsion. Additionally, we could conclude that the silicon powder created could be used for producing feigned soil for fostering pharmaceutical flora in the ISS to discover scarce-drugs for high-endurance health care management. It leads to say that one can aim for farming medicinal plants in the space lab for discovering suitable drugs for enhancing the heat capacity ratio of blood for reducing the risk of asymptomatic stroke and acute heart failure in the gravity and microgravity conditions presumably due to the variations in blood viscosity and turbulence level in the circulatory systems of human being and animals, as recommended by Kumar et $\mathrm{al}^{3,24,25} \mathrm{It}$ is known that cardiovascular risk is higher in astronauts/cosmonaut but the fundamental cause of such risk is still unknown to medical science. ${ }^{3,25,41,42}$ Delp et al ${ }^{41}$ highlighted that Apollo lunar astronauts exhibit higher cardiovascular disease mortality. It is important to note that the world-wide space agencies and nations are contemplating for the long manned missions to Mars and the Moon. In such manned missions, human fitness risks could be escalated as the voyage goes afar the Earth's shielding magnetosphere into the strong deep space radiation milieu. Therefore, suitable drug discovery is inevitable for increasing the thermal tolerance level ${ }^{3}$ for reducing the cardiovascular risk of the inhabitants (human being/animal) of the space vehicle or space lab. Of late (2019), researchers reported that being in microgravity can have abnormal physiological changes on the body, including people's blood flow backward, with unknown consequences to cerebral venous out flow. ${ }^{42-44}$ All these findings lead to say that high endurance health care management is required for reducing the risk of cardiovascular disease mortality of astronauts/cosmonaut for conducting experiments in the space labs. Further discussion on the medical application of our study is beyond the scope of this short communication. 
Briefly, our theoretical concept study will create a win-win situation through real-time experiments in the orbiting space lab by recycling the space debris lucratively, for creating end products for the benefits to humanity. We concluded that the proof of the theoretical concept presented herein could be implemented in real time in any space lab for the debris mitigation and recycling in accordance with the procedural requirements set for meeting the safety and mission assurance. ${ }^{13,43,45-47}$ Barring all limitations, highlighted in the subsequent section, we concluded that the space debris-recycling and the energy conversion system described methodologically herein are viable options for producing the end products in the ISS for various biological and aerospace applications in the future for the benefits to humanity.

\section{5 | LIMITATIONS AND FUTURE WORKS}

The space station extends a scientific platform for in vitro studies and research to improve the quality of life, simplify space voyaging, and well recognize the universe. Although such facilities are extended to researchers the space agencies are rarely conducting in vitro microgravity combustion studies for burn rate modeling mainly due to safety apprehensions. This is the main limitation of this study. The fact is that materials are easier to ignite in microgravity due to the reduced natural convective cooling from the fuel plane. To overcome this lacuna and further reducing the empirical burn rate prediction experiments in the ISS, we propose through the novel Energetic Materials Genome (EMG) approach to decide the constitution of propellant from the existing list of space debris powder that offers the desired burning rate for in vitro qualification studies for the microgravity propulsion system design in the space lab profitably. ${ }^{48,49}$ Note that additional materials (fuel/oxidizer) and/or additives must be available on board for making solid propellants for getting the desirable specific impulse of various space propulsion systems at different scales, as the case may be. Additionally, sufficient water must be produced using on-board fuel-cell for vegetation. These are identified as minor limitations in making the desirable end product without any prerequisite.

The EMG initiative offers for data sharing and analysis that could provide a considerably greater comprehension on the inventors' for creating novel materials successfully. This venture will develop the enhanced in silico capabilities, data management, and a blended engineering technique for the material utilization. The execution of this initiative would require a sustained exertion from all engineering sectors in the discovery of the new materials in the space station. Briefly, we suggest through this short communication a novel method in the accelerated development of new solid propellants and artificial soil through the space debris recycling at the space platform through the EMG approach and machine learning for meeting the future needs of humankind.

In the first phase of our future work, the processing and recycling of the space debris will be provided through Neural Network based control. In the second phase, we will develop the model experimental setup for processing and recycling of the space debris in the benchmark laboratories through international collaboration. Subsequently, this experimental setup will be installed at the actual or simulated platform of the Space Lab as the case may be. In its basic form, the Neural Network-Based Smart Space Recycler would include a large parabolic reflector (50-100 feet in diameter) available in the space industry as a spherical crucible with multiple compartments made with high-temperature materials and different DHEM-operated robotic arms with the Diamond-Graphene net or with other composite materials for seizing hypervelocity flying space debris effectively.

\section{ACKNOWLEDGEMENTS}

The first author would like to thank Kumaraguru College of Technology, India.

\section{PEER REVIEW INFORMATION}

Engineering Reports thanks the anonymous reviewers for their contribution to the peer review of this work.

\section{PEER REVIEW}

The peer review history for this article is available at https://publons.com/publon/10.1002/eng2.12317.

\section{AUTHOR CONTRIBUTIONS}

Amrith Mariappan: Conceptualization; data curation; formal analysis; investigation; methodology; software; writing-original draft. V. R. Sanal Kumar: Data curation; project administration; supervision; writing-review and editing. Steve J Weddell: Data curation; investigation; methodology; writing-original draft. Vishnu Anand Muruganandan: Data curation; resources; validation. In-Seuck Jeung: Data curation; methodology; resources. 


\section{CONFLICT OF INTEREST}

The authors declare no potential conflict of interest.

\section{DATA AVAILABILITY STATEMENT}

The data that support the findings of this study are available from the corresponding author upon reasonable request.

\section{ORCID}

Amrith Mariappan (D) https://orcid.org/0000-0001-6857-1916

V. R. Sanal Kumar (10 https://orcid.org/0000-0002-5643-7223

Stephen J. Weddell (iD https://orcid.org/0000-0002-2345-0077

Vishnu Anand Muruganandan (10) https://orcid.org/0000-0001-9212-2803

In-Seuck Jeung (1) https://orcid.org/0000-0001-5443-9439

\section{REFERENCES}

1. International Space Station Program, Science Forum. Robinson J Costello K, Executive Summary. eds. International Space Station Benefits for Humanity. International Space Station 1. 3rd ed. United States: NP-2018-06-013-JSC NASA; 2018:1-217. https://www.nasa.gov/sites/ default/files/atoms/files/benefits-for-humanity_third.pdf.

2. Klinkrad H. Space debris. Encyclopedia of Aerospace Engineering. 2010. https://doi.org/10.1002/9780470686652.eae325.

3. Sanal Kumar VR, Sankar V, Chandrasekaran N, et al. Sanal Flow choking: a paradigm shift in computational fluid dynamics code verification and diagnosing detonation and hemorrhage in real-world fluid-flow systems. Glob Chall. 2020;4:2000012. https://doi.org/10.1002/ gch2.202000012.

4. Liou J-C, Kieffer M, Drew A, Sweet A. The 2019 U.S. Government orbital debris mitigation standard practices. Orbital Debris Q News. 2020;24(1):4-9. https://orbitaldebris.jsc.nasa.gov/quarterly-news/pdfs/odqnv24i1.pdf.

5. Liou J-C. An active debris removal parametric study for LEO environment remediation. Adv Space Res. 2011;47:1865-1876. https://doi. org/10.1016/j.asr.2011.02.003.

6. Liou J-C, Johnson NL. Planetary science: risks in space from orbiting debris. Science. 2006;311(5759):340-341. https://doi.org/10.1126/ science.1121337.

7. Liou J-C, Johnson NL. Controlling the growth of future LEO debris populations with active debris removal. Acta Astronaut. 2010;66:648-653. https://doi.org/10.1016/j.actaastro.2009.08.005.

8. Smirnov NN. Space Debris - Hazard, Evaluation and Mitigation, ISBN 0-415-27907-0, ISSN 1026-2660, London ; New York : Taylor \& Francis, 2002. Adv Space Res. 2002;30(2):427-428. https://doi.org/10.1016/S0273-1177(02)00366-6.

9. United Nations General Assembly, Committee on the Peaceful Uses of Outer Space. Scientific and Technical Subcommittee Fifty-fourth session. A/AC.105/C.1/111; 30 January-10 February 2017; Vienna, Austria. https://undocs.org/A/AC.105/C.1/111. Accessed Date: June 7, 2020.

10. Palmroth M, Praks J, Vainio R, et al. FORESAIL-1 cubesat mission to measure radiation belt losses and demonstrate de-orbiting. J Geophys Res Space Phys. 2019;124(7):5783-5799. Accessed Date: June 7, 2020. https://doi.org/10.1029/2018ja026354.

11. Slíz-Balogh J, Horváth D, Szabó R, Horváth G. Dynamics of spherical space debris of different sizes falling to Earth. Astronom Nachrichten. 2020;341(3):245-257. https://doi.org/10.1002/asna.202023688.

12. Rogerio Atemde Carvalho, Jaime Estela, and Martin Langer (Eds.), Nanosatellites: Space and Ground Technologies, Operations and Economics, 1st: John Wiley \& Sons Ltd. 2020. https://doi.org/10.1002/9781119042044.

13. Zinner N, Williamson A, Brenner K, et al., Junk Hunter: autonomous rendezvous, capture, and de-orbit of orbital debris. Paper presented at: AIAA SPACE 2011 Conference \& Exposition; 2011; Long Beach, CA. https://doi.org/10.2514/6.2011-7292.

14. Deepaa Anandhi RR, Akash Chandran A, Hemasai ND, Mani S, Sanal Kumar VR, Statistical studies on space launches and the need for active debris removal system. Paper presented at: AIAA SPACE 2015 Conference and Exposition. Pasadena, CA; 2015. https://doi.org/10. 2514/6.2015-4573.

15. Mariappan A, Sanal Kumar VR, Anand V, Weddell S, Jeung I-S. A conceptual method to recycle space debris into fuels and artificial soil in the ISS for numerous applications. Paper presented at: AIAA Propulsion and Energy 2019 Forum. Indianapolis, IN; August 2019. 19-21. https://doi.org/10.2514/6.2019-4157.

16. Weddell SJ, Clare RM, Lambert A. Near earth object image restoration with multi-object adaptive optics. In: Flohrer T, Jehn R, Schmitz F, eds. Proceedings of the 1st NEO and Debris Detection Conference. Darmstadt, Germany: ESA Space Safety Programme Office; 2019 http:// neo-sst-conference.sdo.esoc.esa.int.

17. Sanal Kumar VR, Sharan S, Kumar A, et al. Dual-head electromagnetic variable sweeping speed space broom for space debris mitigation. Paper presented at: AIAA SPACE 2016. Long Beach, CA; September 13-16, 2016. https://doi.org/10.2514/6.2016-5522.

18. Jiang $\mathrm{H}$ et al. A robotic device using gecko-inspired adhesives can grasp and manipulate large objects in microgravity. Sci Robot. 2017;2(7):eaan4545. https://doi.org/10.1126/scirobotics.aan4545.

19. Kessler DJ, Cour-Palais BG. Collision frequency of artificial satellites: The creation of a debris belt. J Geophys Res. 1978;83(A6):2637. https://doi.org/10.1029/ja083ia06p02637. 
20. SDO. ESA's annual space environment report. Report No. GEN-DB-LOG-00271-OPS-SD. European Space Operations Centre, ESA Space Debris Office, Issue 3.2; July 17, 2019. https://www.sdo.esoc.esa.int/environment_report/Space_Environment_Report_latest.pdf. Accessed Date: September 1, 2019.

21. Gasser F. Abdelal, Nader Abuelfoutouh, Ahmed H. Gad, Finite Element Analysis for Satellite Structures: Applications to Their Design, Manufacture and Testing, https://doi.org/10.1007/978-1-4471-4637-7, Springer-Verlag London, UK, 2013.

22. Frost C, Agasid E, Shimmin R, et al. State of the Art of Small Spacecraft Technology, Structures, Materials and Mechanisms. United States: NASA Ames Research Center, Mission Design Division; 2015, NASA/TP-2015-216648/REV1.

23. Tajmar M. Homopolar artificial gravity generator based on frame-dragging. Acta Astronaut. 2010;66(9-10):1297-1301. https://doi.org/10. 1016/j.actaastro.2009.10.022.

24. Sanal Kumar VR, Sankar V, Chandrasekaran N, et al. Boundary layer blockage, venturi effect and cavitation causing aerodynamic choking and shock waves in human artery leading to hemorrhage and massive heart attack - a new perspective. Paper presented at: 2018 Applied Aerodynamics Conference; 2018; Atlanta, GA. https://doi.org/10.2514/6.2018-3962.

25. Sanal Kumar VR, Sundararam Bharath R, Radhakrishnan PK et al. Nanofluid flow choking and spaceflight effects on cardiovascular risk of astronauts - A new perspective. Paper presented at: The 2021 AIAA SciTech Forum; January 11-15, 2021 (Accepted). OSF Preprints; February 5, 2020. https://doi.org/10.31219/osf.io/bce2n.

26. Takahashi K, Charles C, Boswell RW, Ando A. Demonstrating a new technology for space debris removal using a bi-directional plasma thruster. Nature Sci Rep. 2018;8:14417. https://doi.org/10.1038/s41598-018-32697-4.

27. Deorbit E. ESA's active debris removal mission. 2016. https://www.esa.int/spaceinvideos/Videos/2016/05/ESA_s_active_debris_removal_ mission_e.Deorbit.

28. Sathish Paulraj Gundupalli, Subrata Hait, Atul Thakur, A review on automated sorting of source-separated municipal solid waste for recycling, Waste Manage, 60, 2017, pp 56-74, https://doi.org/10.1016/j.wasman.2016.09.015.

29. Manouchehri H-R. Application of optoelectronic sorting technique for upgrading minerals and wastes. Paper presented at: Konferens i mineralteknik 2006: 07/02/2006-08/02/2006; 2006; Föreningen Mineralteknisk Forskning/Swedish Mineral Processing Research Association. https://www.diva-portal.org/smash/get/diva2:1003813/FULLTEXT01.pdf.

30. Koyanaka S, Kobayashi K. Automatic sorting of lightweight metal scrap by sensing apparent density and three-dimensional shape. Resourc Conserv Recycl. 2010;54(9):571-578. https://doi.org/10.1016/j.resconrec.2009.10.014.

31. Oleg D. Neikov, Naboychenko SS, Yefimov NA, Handbook of Non-Ferrous Metal Powders: Technologies and Applications, 2nd, 2019: Russia: Elsevier Ltd. https://doi.org/10.1016/C2014-0-03938-X.

32. Tubana BS, Babu T, Datnoff LE. A review of silicon in soils and plants and its role in US agriculture. Soil Sci. 2016;181(9/10):393-411. https://doi.org/10.1097/ss.0000000000000179.

33. Price S, Phillips T, Knier G. Staying cool on the ISS. March 20, 2001. https://science.nasa.gov/science-news/science-at-nasa/2001/ ast21mar_1.

34. The truth about space debris,. Published on April 26, 2019. https://www.youtube.com/watch?v=itdYS9XF4a0\%feature=youtu.be.

35. Bairwa A, Reddy AK, Singh G, Sharma VK. Granulation and atomization process for production of metal granules and powders. Int J Mech Prod Eng. 2018;6(4):24-28.

36. Asgarian A, Tang Z, Bussmann M, Chattopadhyay K. Water atomisation of metal powders: effect of water spray configuration. Powder Metall. 2020;63(4):288-299. https://doi.org/10.1080/00325899.2020.1802558.

37. Boušková A, La Cour Jansen J, Persson E. The effect of operational temperature on dewatering characteristics of digested sludge. J Residuals Sci Technol. 2006;3(1):43-49.

38. Bussard RW. Galactic matter and interstellar flight. Acta Astronaut. 1960;6(4):179-195. https://machinman.net/intersideral/references/ bussard.pdf.

39. Taranovich S. International Space Station (ISS) power system. January 26, 2014. https://www.edn.com/design/power-management/ 4427522/International-Space-Station-ISS-power-system.

40. Easton RL, Votaw MJ. Vanguard I IGY satellite (1958 Beta). Rev. Sci. Instrum. 1959;30:70-75. https://doi.org/10.1063/1.1716492.

41. Delp M, Charvat J, Limoli C. et al. Apollo lunar astronauts show higher cardiovascular disease mortality: possible deep space radiation effects on the vascular endothelium. Sci. Rep. 2016; 6(1):29901. https://doi.org/10.1038/srep29901.

42. Wilson C. Low gravity in space made some astronauts' blood flow backwards, SPACE. New Scientist. 2019;244(3257):9.

43. Wormnes K, Le Letty R, Summerer L, et al. ESA technologies for space debris remediation. Paper presented at: Proceedings of the 6th European Conference on Space Debris; April 22-25 2013 (ESA SP-723); Darmstadt, Germany. https://conference.sdo.esoc.esa.int/proceedings/ sdc6/paper/116/SDC6-paper116.pdf.

44. Marshall-Goebel K, Laurie SS, Alferova IV, et al. Assessment of jugular venous blood flow stasis and thrombosis during spaceflight. JAMA Netw Open. 2019;2(11):e1915011. https://doi.org/10.1001/jamanetworkopen.2019.15011.

45. Garcia M. Space debris and human spacecraft. 2016. www.nasa.gov/mission_pages/station/news/orbital_debris.html.

46. Orbitaldebris. NASA procedural requirements for limiting orbital debris and evaluating the meteoroid and orbital debris environments. NASA procedural requirements. Office of Safety and Mission Assurance, NPR 8715.6B, February 16, 2017. https://orbitaldebris.jsc.nasa. gov/library/npr_8715_006b_.pdf.

47. Wilcutt TW. NASA technical standard, process for limiting orbital debris. NASA-STD-8719.14B-2019-04-25, April 25, 2019. https:// standards.nasa.gov/standard/nasa/nasa-std-871914. 
48. Abrukov VS, Lukin AN, Chandrasekaran N, et al. Genome approach and data science methods for accelerated discovery of new solid propellants with desired properties. AIAA Propulsion and Energy Forum Paper No. AIAA 2020-3929; August 24-28, 2020. https://doi.org/ 10.2514/6.2020-3929.

49. Mariappan A, Choi H, Abrukov VS, et al. The application of the energetic materials genome approach for development of the solid propellants through the space debris recycling at the space platform. AIAA Propulsion and Energy Forum Paper No. AIAA 2020-3898, August 24-28, 2020. https://doi.org/10.2514/6.2020-3898.

\section{AUTHOR BIOGRAPHIES}

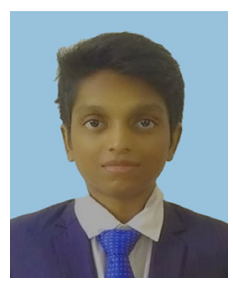

Amrith Mariappan is the founder and Chief Executive Officer of AARIK Aerospace Company, India and currently pursuing his graduate degree course in Aerospace Engineering at the State University of New York at Buffalo, U.S.A. He earned his bachelor's degree in aeronautical engineering from Kumaraguru College of Technology, Anna University, India. He was an intern in the Department of Aerospace Engineering, KAIST, South Korea. He was a project trainee on an Indo-Russian project on Development of the Multifactorial Computational Models of the Solid Propellant Combustion by Means of Data Science Methods. He is having collaborative research works with Megaputer Tech, Chuvash State University and Western-Caucasus Research Center (WCRC), of Russian Federation. Space debris recycling in the space station, ANN modeling, design of planet landers and Graphene composite materials for Space application are his current research interest. He is a recipient of the First Prize and People Choice's Award in the LaunchPad Startup Weekend competition organized by Techstars Startup Weekend conducted in the University at Buffalo which was sponsored by Godaddy and Techstars, USA. He is a student member of AIAA.

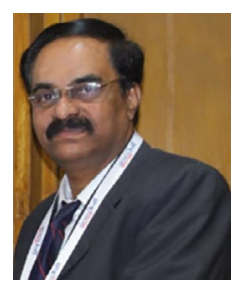

V. R. Sanal Kumar is a professor of aeronautics and a rocket scientist affiliated with the Indian Space Research Organisation since 1992. He earned his Ph.D in the propulsion stream of aerospace engineering from the Indian Institute of Science (IISc), Bangalore. He received his master's degree in propulsion engineering with distinction. He is a receipt of the young scientist award from the Indian National Science Academy (INSA), the apex scientific body of India. He was an INSA-KOSEF postdoctoral fellow and a scientific ambassador to South Korea. Dr.Kumar's name is figured for the future Nobel Prize on his theoretical discovery on the phenomenon of Sanal flow choking (PMCID: PMC7267099), which could predict the asymptomatic heart failure and also the deflagration to detonation transition in the real world flows. He is leading the India-US joint research team on myocardial infarction in collaboration with AIIMS, New Delhi, Georgia Tech. U.S.A., and NASA. He was a visiting professor in Japan and served various academic and administrative positions in India including the head of an institution affiliated to Visvesvaraya Technological University. He is a reviewer of world ranking universities and an Editor/reviewer of various journals and conferences. His research interests are the design and development of aerospace vehicles for satellite launching and planetary exploration, the design of planet landers and rovers, internal flow simulation of solid, hybrid and cryogenic rockets, biofluid dynamics, Nano science and technology, risk assessment of asymptomatic cardiovascular diseases during the human space flight. He is an Indo-Russian project coordinator and pursuing collaborative research worldwide on multidisciplinary topics. He is a member of the American Heart Association.

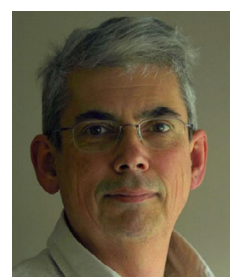

America.

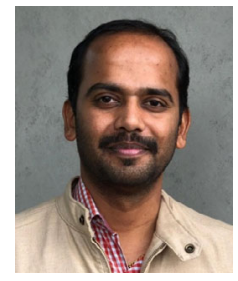

Stephen Weddell received his MAppSc degree in Electrical \& Computer Engineering from Curtin University, Australia, and PhD degree in Electrical \& Electronic Engineering from University of Canterbury, New Zealand. He is a Senior Lecturer, Leader of the Computational Design and Adaptation group, and past Director of Computer Engineering Studies at University of Canterbury. His research interests are in image and digital signal processing, machine teaming, neuroengineering, adaptive optics, brain computer interfaces, systolic computer architectures, and high-performance computing. He is a Senior Member of IEEE and the Optical Society of

Vishnu Anand Muruganadan is a Post-Doctoral Research Fellow in the Department of Electrical \& Computer Engineering, University of Canterbury, New Zealand. He received his bachelor's degree in Aeronautical engineering from Kumaraguru College of Technology, Anna University, India and master's degree in Space Science and Technology from Julius-Maximilians-University Würzburg, Germany. He earned his Ph.D degree in Aerospace Engineering from Seoul National University, the Republic of Korea. 


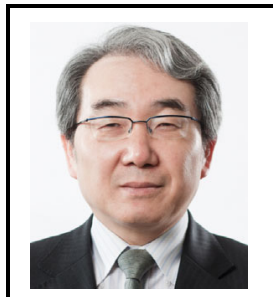

Professor Emeritus In-Seuck Jeung has been a professor of aerospace engineering at Seoul National University (SNU), the Republic of Korea since 1984. He received his B.S, M.S and Ph.D degrees from SNU. He served as a visiting scientist, honorary fellow and visiting professor at Hosei University, University of Minnesota and University of California, Irvine. He has been an associate editor of The Proceedings of the Combustion Institute, Transactions of Japan Society for Aeronautical and Space Sciences/Aerospace Technology Japan, and Topical Editor of Energies, also an editorial member of Progress in Energy and Combustion Science, the international advisory committee of the International Symposium on Shock Waves Colloquium, Colloquium Co-Chair of the International Symposium on Combustion, Asia-Pacific Conference on Combustion, Asian-Pacific International Symposium on Aerospace Technology, the Asian Joint Conference on Propulsion \& Power. His research interests include scramjet and ramjet, gas turbine, ram accelerator, ramjet intake test, the hydrogen leak explosion, laser propulsion, aero-optics and hypersonic aerothermodynamics. He joined HyShot scramjet combustor flight test, working on the design and operation of 2 CubeSats of QB50 Program (SNUSAT-1, -1b) and third CubeSat of KARI Program (SNUSAT-2). He is an Associate Fellow of AIAA.

How to cite this article: Mariappan A, Kumar VRS, Weddell SJ, Muruganandan VA, Jeung I-S. Theoretical studies on space debris recycling and energy conversion system in the International Space Station. Engineering Reports. 2020;e12317. https://doi.org/10.1002/eng2.12317 